\title{
Plasma Adrenaline and Noradrenaline Concentrations in Diabetic Patients With and Without Autonomic Neuropathy at Rest and During Sympathetic Stimulation
}

\author{
F.Caviezel ${ }^{1}$, G. B.Picotti ${ }^{3}$, A. Margonato ${ }^{2}$, G. Slaviero ${ }^{2}$, M.D. Galva ${ }^{3}$, P.Camagna $^{2}$, G.P. Bondiolotti ${ }^{3}$, \\ M.O.Carruba ${ }^{3}$, and G. Pozza ${ }^{2}$ \\ Departments of ${ }^{1}$ Experimental Endocrinology and ${ }^{2}$ Clinical Medicine, San Raffaele Hospital and ${ }^{3}$ Department of Pharmacology, \\ School of Medicine, University of Milan, Italy
}

Summary. Plasma concentrations of adrenaline and noradrenaline were measured radio-enzymatically in nine patients with diabetic autonomic neuropathy, seven diabetic patients without autonomic neuropathy and nine normal subjects, in the recumbent position and after standing. Furthermore, in six patients with autonomic neuropathy and in the normal subjects, plasma noradrenaline and adrenaline concentrations were determined during and after cyclo-ergometer exercise. No differences in plasma adrenaline concentrations were found at any time in the study. Basal plasma noradrenaline levels were significantly lower in diabetic patients with autonomic neuropathy than in the non-neuropathic diabetics or healthy control subjects. After standing, plasma noradrenaline rose to significantly higher levels in both control and diabetic subjects without neuropathy than in the patients with autonomic neuropathy. During exercise (up to $100 \mathrm{~W}$ load), plasma noradrenaline rose to similar levels in healthy controls and in patients with diabetic neuropathy. These data indicate that in diabetic autonomic neuropathy there is reduced peripheral neurosympathetic tone at rest but a normal response to moderate exercise. Blunted neurosympathetic responses to standing seem to be a consistent feature of diabetic autonomic neuropathy, particularly in those patients with severe postural hypotension.

Key words: Plasma catecholamines, adrenaline, noradrenaline, sympathetic nervous activity, diabetes mellitus, autonomic neuropathy, postural stimulation, orthostatic hypotension, muscular exercise.
Autonomic neuropathy in diabetes mellitus produces a variety of different symptoms and signs due to variable involvement of the sympathetic and parasympathetic branches of the autonomic nervous system $[6,14,16]$.

Plasma catecholamine levels have been investigated in only a few studies in recent years, as a possible humoral index of sympathetic function in complicated or uncomplicated diabetes. While the results obtained from these studies indicate that plasma catecholamine levels in uncomplicated diabetes are normal, the frequency of sympathetic deficiency, as reflected by subnormal plasma noradrenaline concentrations, in diabetic autonomic neuropathy and its possible importance in relation to symptoms, such as postural hypotension, is less clear $[1,9,10,12,19]$. This uncertainty could be due, at least in part, to difficulties in the accurate measurement of catecholamine responses and also in the characterization of diabetic autonomic neuropathic syndromes.

The present investigation was aimed at evaluating peripheral sympathetic function and reactivity to appropriate stimuli, such as standing and muscular exer- cise, in diabetic patients with autonomic neuropathy, compared with diabetics without neuropathy and normal subjects. For this purpose, the presence of diabetic autonomic neuropathy was ascertained from a series of clinical and instrumental evaluations. Plasma adrenaline and noradrenaline concentrations, measured by a sensitive and specific radio-enzymatic method, were utilized as indices of neurosympathetic and adrenomedullary function $[4,5]$.

\section{Patients and Methods}

Nine diabetic patients with autonomic neuropathy (mean age 37 years, range $24-49$ years, eight men and one woman), seven diabetic patients without signs of peripheral autonomic or somatic neuropathy (mean age 37 years, range 23-47 years, six men and one woman) and nine healthy volunteers (mean age 33 years, range $23-50$ years, eight men and one woman) were admitted to the study after informed consent was obtained.

Autonomic neuropathy was detected by taking careful histories and measuring parameters, such as the response during the Valsalva manoeuvre and the standing test (Table 1). The response to the Valsalva manoeuvre was expressed as Valsalva ratio: values of 1.1 or less 
Table 1. Clinical data for nine patients with diabetic autonomic neuropathy

\begin{tabular}{|c|c|c|c|c|c|c|c|c|c|}
\hline Patient & Sex & $\begin{array}{l}\text { Age } \\
\text { (years) }\end{array}$ & $\begin{array}{l}\text { Duration of } \\
\text { diabetes } \\
\text { (years) }\end{array}$ & $\begin{array}{l}\text { Type of } \\
\text { therapy }\end{array}$ & Other conditions & Symptoms & $\begin{array}{l}\text { Postural } \\
\text { hypotension }\end{array}$ & $\begin{array}{l}\text { Valsalva } \\
\text { ratio }\end{array}$ & $\begin{array}{l}\text { Abnormal } \\
\text { electro- } \\
\text { neurography }\end{array}$ \\
\hline 2 & $\mathbf{M}$ & 36 & 16 & Insulin & None & $\mathrm{a}, \mathrm{c}$ & + & 1.15 & + \\
\hline 3 & M & 39 & 3 & Insulin & Retinopathy & a & - & 1.04 & + \\
\hline 4 & $\mathrm{~F}$ & 36 & 14 & Insulin & $\begin{array}{l}\text { Retinopathy, mild } \\
\text { hypertension }\end{array}$ & b & + & not performed & + \\
\hline 7 & M & 43 & 6 & Oral & None & $a, c$ & + & 1.15 & not performed \\
\hline 8 & M & 40 & 14 & Insulin & $\begin{array}{l}\text { Retinopathy, renal } \\
\text { failure, hypertension }\end{array}$ & $a, b, c, d$ & + & 1.01 & + \\
\hline 9 & M & 35 & 18 & Insulin & $\begin{array}{l}\text { Retinopathy, renal } \\
\text { failure, hypertension }\end{array}$ & $\mathrm{a}, \mathrm{b}, \mathrm{c}, \mathrm{d}$ & + & not performed & + \\
\hline
\end{tabular}

$\mathrm{a}=$ impotence $; \mathrm{b}=$ impaired perception of hypoglycaemia $; \mathrm{c}=$ post-prandial sweating $; \mathrm{d}=$ diabetic diarrhoea. $+=$ present $;-=\mathrm{absent}$

Table 2. Plasma adrenaline and noradrenaline concentrations, heart rate, systolic and diastolic blood pressure in diabetic patients with and without autonomic neuropathy and in non-diabetic control subjects in the supine position and after 5 min standing

\begin{tabular}{|c|c|c|c|c|c|c|c|c|c|}
\hline & \multicolumn{3}{|c|}{ Healthy subjects } & \multicolumn{3}{|c|}{ Diabetics without neuropathy } & \multicolumn{3}{|c|}{ Diabetics with neuropathy } \\
\hline Noradrenaline (pg/ml) & $275 \pm 38$ & $574 \pm 94$ & $299 \pm 53$ & $257 \pm 22$ & $482 \pm 40$ & $225 \pm 34$ & $169 \pm 27^{\mathrm{a}, \mathrm{d}}$ & $312 \pm 35^{\mathrm{a}, \mathrm{e}}$ & $143 \pm 30^{\mathrm{a}}$ \\
\hline $\begin{array}{l}\text { Systolic blood pressure } \\
(\mathrm{mmHg})\end{array}$ & $119 \pm 4$ & $123 \pm 5$ & $4 \pm 3$ & $128 \pm 4$ & $138 \pm 6$ & $10 \pm 3$ & $135 \pm 6^{\mathrm{a}}$ & $124 \pm 5$ & $-11 \pm 2^{c, f}$ \\
\hline $\begin{array}{l}\text { Diastolic blood pressure } \\
(\mathrm{mmHg})\end{array}$ & $75 \pm 2$ & $82 \pm 2$ & $7 \pm 2$ & $85 \pm 2^{b}$ & $91 \pm 2^{b}$ & $6 \pm 2$ & $85 \pm 2^{b}$ & $86 \pm 2$ & $1 \pm 2^{\mathrm{a}}$ \\
\hline
\end{tabular}

Results are expressed as mean \pm SEM of nine healthy subjects, seven diabetic patients without and seven with autonomic neuropathy. $\Delta=$ absolute increments over basal (supine) values. Statistical significance among groups: ${ }^{\mathrm{a}} p \leqq 0.05 ;{ }^{\mathrm{b}} p \leqq 0.01 ;{ }^{\circ} p \leqq 0.001$ versus normal subjects; ${ }^{\mathrm{d}} p \leqq 0.05 ;{ }^{\mathrm{e}} p \leqq 0.01 ;{ }^{\mathrm{f}} p \leqq 0.001$ versus diabetic patients without neuropathy. For significance versus supine position see text

were considered abnormal. Postural hypotension was defined as a fall in systolic blood pressure of $20 \mathrm{mmHg}$ or more $5 \mathrm{~min}$ after standing [7, 25]. Furthermore, electroneurography, which included studies of motor and sensory nerve conduction velocity and electromyography, was carried out by the method of Buchtal et al. $[2,3,7]$, to ascertain the presence of somatic neuropathy.

The clinical data for the diabetic patients with neuropathy are given in Table 1. Patients 8 and 9 also had renal failure, a condition which per se can alter plasma catecholamine concentrations [8, 21]. Therefore, the results for these patients were evaluated separately and not averaged with those for the other neuropathic subjects. Among the seven diabetic patients without autonomic neuropathy, four were on insulin and three on oral hypoglycaemic therapy. The mean duration of diabetes in these patients was $7 \pm 4$ years (SD).

No patient had been in ketoacidosis during the 7 days before the study. No insulin or oral therapy was given to patients on the morning of the test; however, no patient had a blood glucose $\geqq 11.1 \mathrm{mmol} / \mathrm{l}$ at the end of the experiment.

For convenience, all subjects were studied in the afternoon, at least $3 \mathrm{~h}$ after lunch, since a pilot study had shown that blood pressure and catecholamine levels in the standing test were the same in the morning and afternoon. After a 30-min period of rest in the supine position, a catheter (Abbocath-T 18-G $\times 2$ inches) was inserted into an antecubital vein. The cuff of a mercury sphygmomanometer was placed on the opposite arm and electrodes were placed for electrocardiographic recording to determine heart rate and to observe possible changes in the trace.

Thirty minutes later, basal heart rate and blood pressure values were checked and $3 \mathrm{ml}$ of blood were drawn for plasma catechol- amine assay. The patients were then asked to stand up and after $5 \mathrm{~min}$ standing, blood pressure and heart rate were recorded again and blood samples were drawn. The patients then sat on a bicycle ergometer (Ergometry System 380, Elema Schönander, Stockholm, Sweden) and 25 min later underwent three consecutive 5 min exercise periods, one with a 50 and two with $100 \mathrm{~W}$ loads. The limited work load was chosen in case of possible latent cardiovascular disease. Blood samples were drawn immediately before the cyclo-ergometric test, at the end of each $5 \mathrm{~min}$ exercise period, and after 2.5 and $5 \mathrm{~min}$ of recovery. Heart rate and blood pressure were measured at the same times. The diabetic patients without autonomic neuropathy, the two neuropathic subjects with renal failure (nos. 8 and 9) and the hypertensive woman with autonomic neuropathy (no. 4) were not included in this phase of the study.

Adrenaline and noradrenaline levels were measured in $50 \mu \mathrm{l}$ plasma by the radio-enzymatic method of Da Prada and Zürcher [13]. The sensitivity of the assay was $1 \mathrm{pg}$ for both adrenaline and noradrenaline. Intra-assay and inter-assay coefficients of variation (on 12 determinations) were 9.6 and 12.1 for adrenaline; 7.2 and 9.0 for noradrenaline. Statistical analysis was performed by the two-tailed paired or unpaired Student's t-test. Data are expressed as mean \pm SEM.

\section{Results}

Plasma noradrenaline levels under resting conditions were significantly lower in neuropathic patients than in either diabetic patients without neuropathy or in 


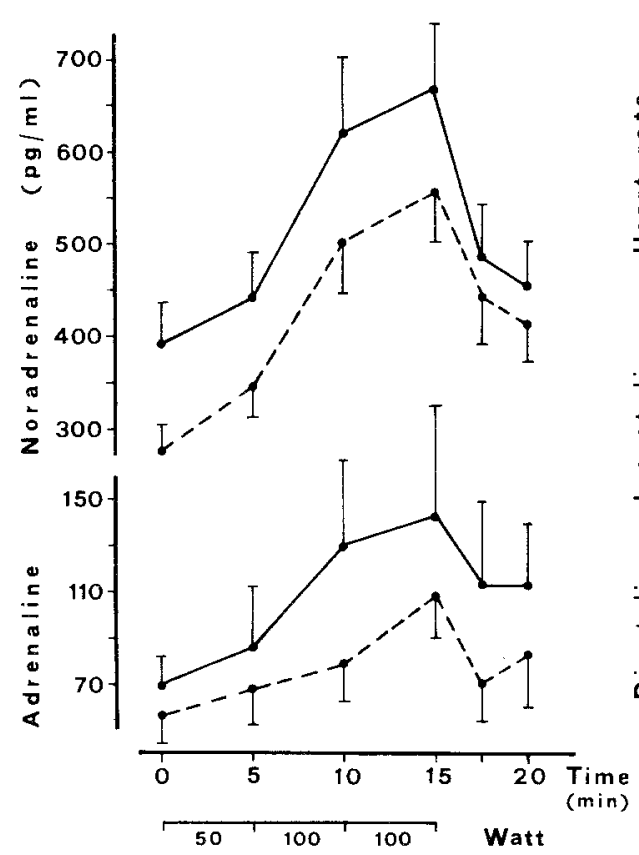

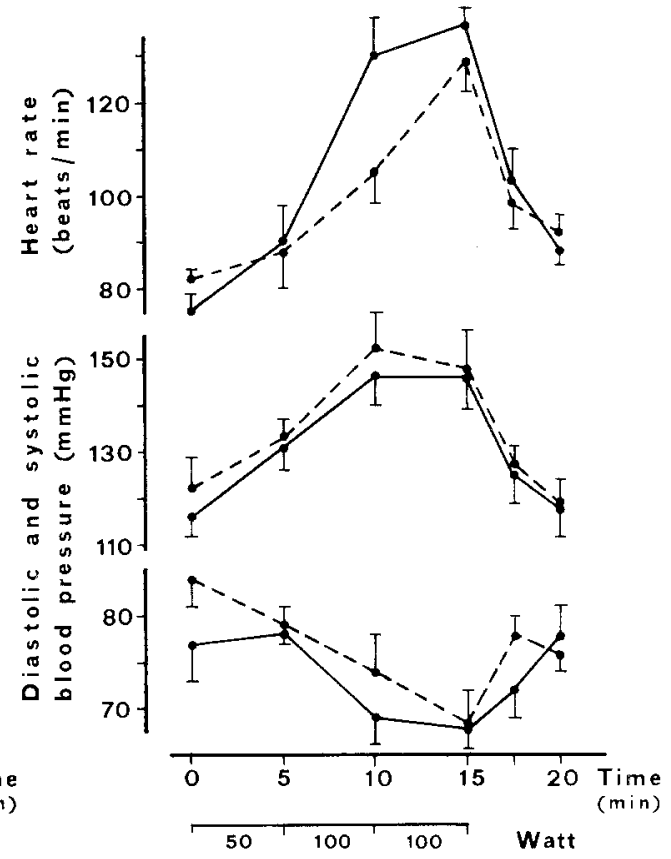

Fig. 1. Plasma adrenaline and noradrenaline concentrations, heart rate, systolic and diastolic blood pressure in diabetic patients with autonomic neuropathy (---) and in non-diabetic control subjects (- - ), during and after cyclo-ergometric exercise in the sitting position. Each point represents the mean \pm SEM for nine healthy subjects or six diabetic patients with autonomic neuropathy. Patients underwent three consecutive $5 \mathrm{~min}$ exercise periods at 50,100 and $100 \mathrm{~W}$ loads. (For statistical significance versus 0 time see text) healthy volunteers (Table 2). Plasma adrenaline levels were not significantly different in the three groups (Table 2).

Both basal systolic and diastolic blood pressure values of the neuropathic diabetic patients were significantly higher than in the normal subjects but were not significantly different from those of the diabetic patients without neuropathy, who also had higher diastolic blood pressure values than control subjects (Table 2). No significant differences in the heart rate under resting conditions were observed in the three groups of patients, although the heart rate was slightly higher in neuropathic diabetic patients than in the other groups. The two neuropathic patients with renal failure (Nos. 8 and 9, Table 1), as in the other neuropathic patients, had low plasma noradrenaline levels (138 and $156 \mathrm{pg} / \mathrm{ml}$ ) but much higher blood pressure values $(190 / 110$ and 210/130 mmHg).

Plasma noradrenaline concentrations rose significantly in all groups of patients after 5 min standing $(p<$ 0.01 in controls, $p<0.001$ in diabetics without neuropathy and $p<0.01$ in diabetics with neuropathy), but to significantly lower absolute values in the neuropathic patients (Table 2). The increase in noradrenaline $(\Delta)$ was less in neuropathic patients than in control subjects (Table 2), although it was similar in the three groups when calculated as a percentage of the basal values $(85$, 88 and $108 \%$ in diabetic patients with neuropathy, without neuropathy and in control subjects, respectively). Plasma adrenaline levels remained unmodified during standing (Table 2).

In both normal subjects and diabetic patients without neuropathy systolic blood pressure tended to increase slightly after 5 min standing, whereas it de- creased in neuropathic patients with a mean variation from basal values significantly different from those of the other two groups (Table 2). Moreover, diastolic blood pressure did not change in diabetic neuropathic patients on standing, whereas it increased significantly $(p<0.05)$ in both normal subjects and in diabetics without neuropathy. Increased heart rate after standing was observed in all three groups (Table 2). However, this increase was statistically significant only in controls $(p<0.01)$ and in diabetics without neuropathy $(p<$ $0.05)$.

The two neuropathic patients with renal failure (Nos. 8 and 9) had severe orthostatic hypotension $(\Delta$ systolic blood pressure: -80 and $-72 ; \Delta$ diastolic blood pressure: -35 and $-30 \mathrm{mmHg}$ after $5 \mathrm{~min}$ standing) with minor changes in plasma noradrenaline concentrations ( $\Delta:-34$ and $+60 \mathrm{pg} / \mathrm{ml}$ plasma).

Plasma noradrenaline levels in the sitting position before cyclo-ergometric exercise were somewhat lower, although not significantly so, in diabetic neuropathic patients than in healthy volunteers (Fig.1). Exercise induced significant increases $(p<0.05$ when compared to basal values from min 10) in plasma noradrenaline concentrations in both neuropathic patients and in normal subjects. Although plasma noradrenaline levels remained lower in neuropathic patients, they did not differ significantly from those of the controls at any time studied (Fig.1). Moreover the absolute noradrenaline increases from pre-exercise values were quite similar in both groups $(\Delta=279 \pm 65$ and $272 \pm 76 \mathrm{pg} / \mathrm{ml}$ plas$\mathrm{ma}$ at $15 \mathrm{~min}$ in neuropathic patients and in controls respectively, corresponding to 102 and $70 \%$ of the basal values). During the $5 \mathrm{~min}$ recovery period after exercise, plasma noradrenaline levels of the controls returned to 
basal values while those of neuropathic patients remained significantly higher $(p<0.05)$ than the basal ones (Fig. 1).

Only moderate increases in plasma adrenaline concentrations were observed in either neuropathic patients or control subjects during exercise, with the increase statistically significant $(p<0.05)$ at $15 \mathrm{~min}$ in the neuropathic patients. Heart rate and systolic blood pressure rose significantly ( $p<0.05$ versus basal values from $\min 10$ ) in both neuropathic patients and control subjects (Fig.1). No significant differences in heart rate and blood pressure were observed between the two groups during exercise.

\section{Discussion}

Evidence for defective peripheral sympathetic function in diabetic autonomic neuropathy based on estimation of plasma noradrenaline levels is rather scanty. Christensen [9] found low total plasma catecholamines (mainly noradrenaline), under basal conditions and after standing, in nine diabetics with peripheral neuropathy. The same investigator found normal basal plasma noradrenaline levels but impaired release during exercise in six juvenile diabetics with autonomic neuropathy [18]. In the study of non-ketotic diabetic patients by Cryer et al. [12], seven of ten patients with postural hypotension had low plasma noradrenaline at rest and after standing. Beretta-Piccoli et al. [1] reported that the incidence of postural hypotension was equally distributed between their diabetic patients with low and normal plasma noradrenaline.

In our study, diabetic subjects with signs of autonomic and peripheral neuropathy had lower basal plasma noradranaline concentrations than either normal subjects or diabetics without neuropathy, while adrenaline levels are similar, indicating decreased noradrenaline release from sympathetic nerve terminals and normal adreno-medullary function at rest.

On standing, neuropathic patients showed a tendency to postural hypotension, which, however, was more pronounced in some patients during preliminary tests than during the experiment. Reflex neurosympathetic activation $[11,20]$ was present, as indicated by the increased plasma noradrenaline concentrations during standing. However, the absolute concentrations were lower and the noradrenaline increments over the basal values were lesser in neuropathic diabetics than in patients with uncomplicated diabetes and in normal subjects.

Since in neuropathic patients the basal neurosympathetic activity was set lower, the question arises whether or not their neurosympathetic response to standing is different from that of healthy individuals with low sympathetic activity. An analysis of the results obtained for 18 normal subjects with basal plasma noradrenaline levels below $200 \mathrm{pg} / \mathrm{ml}$ (mean value $153 \pm$
$7 \mathrm{pg} / \mathrm{ml}$ ), selected from a group of 53 healthy volunteers previously studied for other purposes, showed a neurosympathetic response to postural stimulation which was greater, although not significantly, than that found in our neuropathic diabetics $(350 \pm 26$ pg noradrenaline $/ \mathrm{ml}$ plasma at $5 \mathrm{~min}$ standing, with an increment of $197 \pm 23 \mathrm{pg} / \mathrm{ml}$, corresponding to a $129 \%$ increase over basal value). Therefore, it seems that the neurosympathetic response to standing in our neuropathic patients cannot be considered to be definitely abnormal, even though it appears to be somewhat blunted. It is difficult to know whether this blunted response plays a primary or only a contributory role in the tendency to orthostatic hypotension. However, it is worth noting that patient No.3, who never had postural hypotension, had a noradrenaline response to standing quite similar to those of normal subjects (202 supine and $452 \mathrm{pg} / \mathrm{ml}$ plasma after standing). By contrast, there was either no plasma noradrenaline increase or a markedly defective one, with severe orthostatic hypotension, in the two diabetic neuropathic patients with renal failure and hypertension (Nos. 8 and 9).

When examined for their sympatho-adrenal responses to muscular exercise, the neuropathic diabetics showed sustained increases in plasma noradrenaline, indicating that the sympathetic neuronal systems of these patients are able to persistently increase activity. As shown by the moderate rises in plasma adrenaline, the work load used was too small to markedly influence the adreno-medullary activity, as would a more strenuous effort [19, 22].

A comparative analysis of the neurosympathetic and cardiovascular responses to a standard work load did not show any differences between diabetics with neuropathy and normal subjects. In a previous study, Hilsted et al. [19] found low plasma noradrenaline concentrations in neuropathic diabetics, both in relation to the relative work load and to exhaustion. In our study, the work load was limited and plasma noradrenaline levels were compared only for a standard work load. Since physical work capacity has been shown to be reduced in diabetic neuropathy [18], it is likely that the relative work load in our study was greater for the neuropathic patients than for the control subjects. It should also be noted that Hilsted et al. [19] matched diabetic patients with and without autonomic neuropathy, while our control group consisted of normal subjects as it is known that diabetic patients without neuropathy can have greater plasma catecholamine increases during exercise than healthy subjects [26]. Moreover, our patients did not receive insulin on the day of the experiment, since insulin is known to affect the autonomic nervous system, causing hypovolaemia and lowering cardiac filling pressure [17, 23, 24].

In conclusion, low resting plasma noradrenaline concentrations and blunted noradrenaline responses to standing seem to be consistent features of diabetic autonomic neuropathy, especially in those patients with se- 
vere postural hypotension. It remains unclear whether the blunted noradrenaline response to standing is attributable to a simple defect in efferent sympathetic function or to a more general autonomic disorder involving other components of the baroreceptor reflex arc.

Acknowledgements. The authors thank Professor P. Mantegazza for helpful criticism of the manuscript. The support of the Italian National Research Council (CNR grants Nos. 80.01139.83, Progetto Finalizzato Medicina Preventiva and 78.02043.04) and of the Italian Ministry of Education is gratefully acknowledged.

\section{References}

1. Beretta-Piccoli C, Wedmann P, Ziegler W, Glück Z, Keusch G (1979) Plasma catecholamines and renin in diabetes mellitus. Klin Wochenschr 57: 681-691

2. Buchthal F, Behse F (1978) Sensory action potentials and biopsy of the sural nerve in neuropathy, In: Canal N, Pozza G (eds) Peripheral neuropathies, developments in neurology, vol. 1. Elsevier/North-Holland, Amsterdam New York Oxford, pp 1-22

3. Buchthal F, Pinelli P, Rosenfalck P (1954) Action potential parameters in normal human muscle and their physiological determinants. Acta Physiol Scand 32: 219-229

4. Bühler HU, Da Prada M, Haefely W, Picotti GB (1978) Plasma adrenaline, noradrenaline and dopamine in man and different animal species. J Physiol (Lond) 276:311-320

5. Callingham BA, Barrand MA (1979) The catecholamines. Adrenaline; noradrenaline; dopamine. In: Gray $\mathrm{CH}$, James VHT (eds) Hormones in blood, vol. 2. Academic Press, London, pp 143-207

6. Campbell JW (1976) Diabetic autonomic neuropathy. Br J Clin Pract 30: 153-156

7. Canal N, Comi G, Saibene V, Musch B, Pozza G (1978) The relationship between peripheral and autonomic neuropathy in insulin dependent diabetes: a clinical and instrumental evaluation. In: Canal N, Pozza G (eds) Peripheral neuropathies, developments in neurology, vol 1. Elsevier/North-Holland, Amsterdam New York Oxford, pp 247-255

8. Cannella G, Picotti GB, Movilli E, Cancarini G, Dc Marinis S, Galva MD, Maiorca R (1981) Plasma catecholamine response to postural stimulation in normotensive and dialysis hypotensionprone uremic patients. Nephron 27: 285-291

9. Christensen NJ (1972) Plasma catecholamines in long-term diabetics with and without neuropathy and in hypophysectomized subjects. J Clin Invest 51: 779-787

10. Christensen NJ (1979) Catecholamines and diabetes mellitus. Diabetologia 16: 211-224

11. Cryer PE (1976) Isotope-derivative measurements of plasma norepinephrine and epinephrine in man. Diabetes 25: 1071-1085

12. Cryer PE, Silverberg AB, Shah SD (1978) Plasma catecholamines in diabetes. Am J Med 64: 407-416
13. Da Prada M, Zürcher G (1976) Simultaneous radioenzymatic determination of plasma and tissue adrenaline, noradrenaline and dopamine within the fentomole range. Life Sci 19: 1161-1174

14. Ewing DJ (1978) Cardiovascular reflexes and autonomic neuropathy. Clin Sci Mol Med 55: 321-327

15. Giachetti A (1979) Axoplasmic transport of noradrenaline in the sciatic nerves of spontaneously diabetic mice. Diabetologia 16 : 191-194

16. Giachetti A (1981) Diabetic neuropathies: pathogenetic mechanisms and therapeutic perspectives. Pharmacol Res Commun 13: 101-119

17. Gundersen HJG, Christensen NJ (1977) Intravenous insulin causing loss of intravascular water and albumin and increased adrenergic nervous activity in diabetics. Diabetes 26:551-557

18. Hilsted J, Galbo H, Christensen NJ (1979) Impaired cardiovascular responses to graded exercise in diabetic autonomic neuropathy. Diabetes 28: 313-319

19. Hilsted J, Galbo H, Christensen NJ (1980) Impaired responses of catecholamines, growth hormone, and cortisol to graded exercise in diabetic autonomic neuropathy. Diabetes 29:257-263

20. Kopin IJ, Lake RC, Ziegler M (1978) Plasma levels of norepinephrine. Ann Intern Med 88:671-680

21. Ksiazek A (1979) Dopamine-beta-hydroxylase activity and catecholamine levels in the plasma of patients with renal failure. Nephron 24: 170-173

22. Lütold BE, Bühler FR, Da Prada M (1976) Dynamic von Plasma katecholaminen und $\beta$-Adrenoceptor-Funktionen. Schweiz Med Wochenschr 106: 1735-1738

23. Miles DW, Hayter CJ (1968) The effect of intravenous insulin on the circulatory responses to tilting in normal and diabetic subjects with special reference to baroreceptor reflex block and atypical hypoglycaemic reactions. Clin Sci Mol Med 34: 419-430

24. Page M McB, Watkins PJ (1976) Provocation of postural hypotension by insulin in diabetic autonomic neuropathy. Diabetes 25 : 90-95

25. Pozza G, Canal N, Saibene V, Comi G, Fusi MG, Toussoun J, Rodocanachi M (1979) La neuropatia diabetica. Minerva Gastroenterol 25: 249-264

26. Tamborlane WV, Sherwin RS, Koivisto V, Hendler R, Genel M, Felig P (1979) Normalization of the growth hormone and catecholamine response to exercise in juvenile-onset diabetic subjects treated with a portable insulin infusion pump. Diabetes 28: $785-788$

Received: 9 June 1981

and in revised form: 19 February 1982

Dr. F. Caviezel

Department of Experimental Endocrinology

San Raffaele Hospital

I-20090 Milan Segrate, Italy 